\title{
Distant metastases and synchronous malignancies on FDG-PET/CT in patients with head and neck cancer: a retrospective study
}

Acta Radiologica

2020, Vol. 6I(9) II96-1204

(C) The Foundation Acta Radiologica 2020

\section{(c) (1) (2)}

Article reuse guidelines: sagepub.com/journals-permissions DOI: 10.1 I77/0284|85। I9896344 journals.sagepub.com/home/acr

\author{
Lennart Flygare' $\left(\mathbb{D}\right.$, Amal Al-Ubaedi', Wilhelm Öhman ${ }^{1,2}$ and \\ Susanna Jakobson Mo'
}

\begin{abstract}
Background: Fluorodeoxyglucose positron emission tomography/computed tomography (FDG-PET/CT) has been proven to be a good method to detect distant spread of head and neck cancer (HNC). However, most prior studies are based on Asian populations and may not be directly transferable to western populations.

Purpose: To investigate the frequency and distribution of distant metastases and synchronous malignancies detected by $\mathrm{PET} / \mathrm{CT}$ in HNC in a northern Swedish population.

Material and Methods: All primary whole-body FDG-PET/CT examinations performed on the suspicion of HNC ( $n=524$ patients) between I January 2013 and 31 December 2016 at Umeå University Hospital in Sweden were retrospectively reviewed. After the exclusion of 189 examinations without evidence of primary HNC, 335 examinations were analyzed.

Results: Distant metastases were detected in 10 (3\%) patients, all with advanced primary tumors corresponding to TNM stage 3-4, most frequently in salivary gland adenocarcinoma, where $50 \%$ of patients had distant spread. Four patients had metastases below the diaphragm, representing $20 \%$ of the salivary gland malignancies. In the remaining six patients, metastases were supraphrenic, of which all but one were identified by CT alone. Synchronous malignancies were discovered in 14 (4.2\%) patients, of which five were below the diaphragm.

Conclusion: The overall frequency of distant spread and synchronous malignancy in primary HNC was generally low. However, the risk for distant metastases below the diaphragm was relatively higher in salivary gland adenocarcinoma, supporting whole-body FDG-PET/CT in the primary diagnostic work-up in these patients.
\end{abstract}

\section{Keywords}

Head and neck cancer, metastases, synchronous neoplasms, PET-CT, I8F-FDG

Date received: I5 July 2019; accepted: I December 2019

\section{Introduction}

Head and neck cancer (HNC) is a collective term for tumors in the lips, oral cavity, throat, larynx, nose and sinuses, and salivary glands as well as lymph node metastases of the neck with unknown primary tumor. Within each anatomical group, there are subtypes of malignancies that differ in terms of growth, risk of proliferation, prognosis, and treatment (1).

In Scandinavian countries, $\mathrm{HNC}$ is a relatively rare form of cancer, whereas globally it is a very significant disease group. In the western world, HNC is the fifth to sixth most common type of cancer, while in developing countries it is the second to third most common type of cancer reported (2-5). The majority, approximately

\footnotetext{
'Department of Radiation Sciences, Diagnostic Radiology, Umeå University, Umeå, Sweden

${ }^{2}$ Department of Surgery, Skellefteå Hospital, Skellefteå, Sweden
}

\section{Corresponding author:}

Lennart Flygare, Department of Radiation Sciences, Diagnostic Radiology, Umeå University, 90185 Umeå, Sweden.

Email: lennart.flygare@umu.se 
$60 \%$, of all new cases of $\mathrm{HNC}$ are diagnosed with an advanced tumor disease, that is, stage 3 or 4 (1). As a rule, Swedish patients with suspected malignant tumors in the head and neck area undergo a radiological investigation as part of the primary diagnostic work-up. The methods are primarily computed tomography (CT), magnetic resonance imaging (MRI), fluorine-18fluorodeoxyglucose positron emission tomography/computed tomography (FDG-PET/CT), or ultrasound (1).

The occurrence of distant metastases in patients with $\mathrm{HNC}$ is lower than in many other primary malignancies, in the range of $4 \%-25 \%$, with the lungs, bones, and liver being the most frequent sites (6-12). Distant spread usually occurs late during the course of the disease, while synchronous malignancies may be present in any stage.

Distant metastases and synchronous malignancies at the time of diagnosis are serious findings that have a significant impact on treatment decisions for patients with HNC $(11,13)$. Patients diagnosed with distant spread are often considered incurable and will usually undergo treatment with palliative intent (11).

FDG-PET/CT is one imaging method recommended in the investigation of suspected $\mathrm{HNC}$, according to the Swedish national care program (1). It is well-known that FDG-PET/CT can increase the accuracy of the locoregional staging in $\mathrm{HNC}$ (14-17).

However, most prior studies on the value of FDG$\mathrm{PET} / \mathrm{CT}$ in screening for distant metastases and synchronous malignancies in $\mathrm{HNC}$ are based on Asian populations with a different disease pattern and prevalence compared to western populations and may not be directly transferable to western conditions (15). It is therefore important to assess the frequency of distant metastases and synchronous malignancies in a Scandinavian population in order to evaluate whether FDG-PET/CT is preferable for primary staging or if a CT, MRI, or FDG-PET/MR of the neck combined with a $\mathrm{CT}$ of the thorax might be sufficient as primary work-up in some patients with HNC.

\section{Material and Methods}

In this retrospective study, all patients with a clinical suspicion of a primary HNC who underwent a wholebody FDG-PET/CT at the Department of Radiology at Umeå University Hospital between January 2013 and December 2016 were included. During this period, the local clinical guidelines prescribed that all patients with a suspected $\mathrm{HNC}$, except early-stage laryngeal cancer, should undergo whole-body FDG-PET/CT. Umeå University Hospital is the only PET center in the northern Swedish region, with a catchment area for a population of approximately 0.9 million inhabitants. Scanning was made on a General Electric
DISCOVERY 690 64-slice PET/CT scanner after $6 \mathrm{~h}$ of fasting. Imaging was done $1 \mathrm{~h}$ after intravenous administration of $4 \mathrm{MBq} / \mathrm{kg}$ of $18 \mathrm{~F}-\mathrm{FDG}$. The PET acquisition was made separately for the head and neck region with high-resolution reconstruction (SHARP) in the head and neck area. A standard acquisition protocol and reconstruction was applied for the rest of the body. After PET sampling, a contrast-enhanced CT thorax and abdomen was performed. The neck was then scanned separately using a dedicated, contrastenhanced neck CT protocol. Total scanning time was $45 \mathrm{~min}$. The CT scans and corresponding PET data were fused for integrated interpretation. Follow-up FDG-PET/CT investigations were excluded. Patients with early-stage laryngeal cancer do not routinely undergo FDG-PET/CT and were thus not included in the study. Cases with malignancies other than primary $\mathrm{HNC}$ in the head and neck region-for example, lymphoma, thyroid or esophageal cancer, malignant melanoma of the skin, neck metastases from other types of malignancies and infectious, or other benign changeswere also excluded from the study.

The reports from the FDG-PET/CT investigations were collected from the digital radiology information system. Documentation from multidisciplinary conferences and journal entries on other patient-related information was collected from the digital hospital information system. Sex, age, TNM classification, histopathology, proliferation marker Ki-67, and synchronous malignancies were recorded as background data. Localization of the primary tumor, divided into eight different tumor sites according to the Union for International Cancer Control (UICC) (18), was recorded (i.e. nasal cavity and sinuses, nasopharynx, mouth and lips, oropharynx, hypopharynx, larynx, salivary glands, and unknown primary tumors). Most patients had undergone ultrasound-guided fine needle aspiration cytology (US-FNAC) of pathologically conspicuous lymph nodes in the neck. In addition, the expression of proliferation marker Ki-67 was classified in three levels: grade $1(1 \%-30 \%)$; grade 2 $(30 \%-50 \%)$; and grade $3(>50 \%)$.

The final histopathological diagnosis of the HNC was noted for each case. The histopathological type of synchronous malignancies was also recorded.

The final TNM classification (18) used in this study was decided on in a multidisciplinary conference, weighing together all relevant information available.

\section{Ethical approval}

Approval from the Institutional Review Board was obtained from the regional ethics committee before the study. Since the study was retrospective, informed consent by patients was not required. 


\section{Results}

A total of 524 FDG-PET/CT investigations were performed due to a clinical suspicion of primary $\mathrm{HNC}$ during January 2013 to December 2016. In 335 (64\%) FDG-PET/CT examinations, a primary HNC was discovered in $226(67.5 \%)$ men and $109(32.5 \%)$ women with a mean age of 63 years (age range $=19-93$ years) (Fig. 1, Table 1). The remaining 189 (36\%) studies revealed either a type of malignancy other than primary $\mathrm{HNC}$ or benign changes and were hence excluded from further analysis (Fig. 1). One patient had a presumed primary HNC with lung metastases, but this patient died before the radiologic findings could be verified; hence this case was excluded from the study.

\section{Primary HNC localization}

The most common localization of HNC was in the oropharynx, found in $130 / 335(38.8 \%)$ instances, and in the mouth and lips, found in $115(34.3 \%)$ instances (Table 1). The most predominant histopathological type of HNC was squamous cell carcinoma (SCC), found in $289(86.2 \%)$ patients, followed by adenocarcinoma in $11(3.2 \%)$ cases (Table 1$)$.

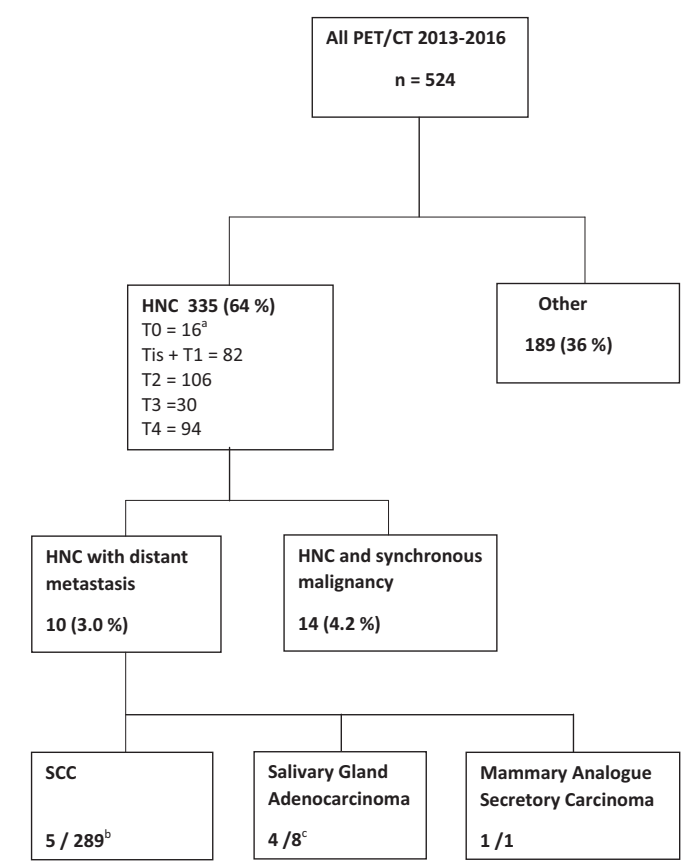

${ }^{\mathrm{a}} \mathrm{T} 0=$ Carcinoma Unknown Primary, in seven patients T-stage was lacking in records. ${ }^{\mathrm{b}} 283$ SCC and 6 basaloid SCC. ${ }^{c} 8$ adenocarcinomas out of 20 salivary gland malignancies.

Fig. I. Flow chart of study design. n, FDG-PET/CT investigations performed on the suspicion of HNC; HNC, head and neck cancer; SCC, squamous cell carcinoma. ${ }^{\mathrm{a}} \mathrm{T} 0$, Carcinoma Unknown Primary. In seven patients T-stage was lacking in records. ${ }^{\mathrm{b}} \mathrm{A}$ total of $283 \mathrm{SCC}$ and six basaloid SCC. 'Eight adenocarcinomas out of 20 salivary gland malignancies.

\section{Distant metastases}

Distant metastases were found in $10(3.0 \%)$ of the 335 FDG-PET/CT studies of patients with primary HNC (Fig. 1). In the 10 patients with distant spreading, a total of 21 distant metastases were found; the locations of these are shown in Table 3. Sixty-seven percent of the distant metastases were located in the thoracic region (Fig. 2). Four patients had distant metastases below the diaphragm; all these patients had a primary salivary gland cancer (Fig. 3).

Locoregional staging (TN category only, without regard to $\mathrm{M}$ ) of the $10 \mathrm{HNCs}$ with distant spread was stage $4 \mathrm{~A}$ in five cases and stage $4 \mathrm{~B}$ in three cases. In two cases, the definite $\mathrm{TN}$ classification was missing in the patient records (Table 2); however, retrospective review of the images revealed that these primary tumors were locally advanced stage 4 .

Five of the 289 HNC patients with SCC had distant metastases. Three of these primary SCC were in the oropharynx, one was located in the hypopharynx and one in the larynx. The other five primary tumors with distant spreading were all major salivary gland carcinomas: four adenocarcinomas (of eight major salivary gland adenocarcinomas) and one was a mammary analogue secretory carcinoma (Table 2 ).

In all, there were a total of 20 primary salivary gland malignancies in our material (Tables 1 and 2).

The rate of proliferation marker $\mathrm{Ki}-67$ in the 10 HNCs with distant metastases classified as grade 3 in five cases and grade 2 in three cases. In two cases, information on Ki-67 was missing (Table 2).

\section{Synchronous malignancies}

A synchronous tumor was discovered in 14 (4.2\%) patients (Fig. 1). None of these exhibited distant spread of HNC. The distribution of synchronous malignancies is shown in Table 3. In all cases of HNC with a synchronous tumor, the primary HNC was SCC, most of them arising from the oral cavity. Eight of 14 synchronous malignancies were found in the neck or thorax. The most common form of synchronous malignancy was thyroid cancer, which occurred in four cases. One synchronous chronic lymphatic leukemia was diagnosed histopathologically and not radiologically. The other five synchronous malignancies were located below the diaphragm (Table 3).

\section{Discussion}

The presence of distant metastases in HNC is crucial for prognosis and treatment decisions, as well as the occurrence of synchronous malignancies, which also may affect treatment decisions. That is one reason why the use of whole-body FDG-PET/CT in primary 
Table I. Anatomical distribution and histologic type of head and neck cancers in 335 patients.

\begin{tabular}{|c|c|c|c|c|c|c|c|c|c|}
\hline \multirow[b]{2}{*}{ Diagnosis } & \multicolumn{9}{|l|}{ Region } \\
\hline & $\begin{array}{l}\text { Nasal cavity } \\
\text { and sinuses }\end{array}$ & Nasopharynx & $\begin{array}{l}\text { Lips and } \\
\text { oral cavity }\end{array}$ & Oropharynx & Hypopharynx & Larynx & $\begin{array}{l}\text { Salivary } \\
\text { glands }\end{array}$ & CUP & $\begin{array}{l}\text { Total } \\
\text { (n (\%)) }\end{array}$ \\
\hline SCC & 9 & 7 & 102 & 121 & 11 & 17 & & 16 & $283(84)$ \\
\hline Adenocarcinoma & 1 & & 4 & & & & 8 & & $13(4)$ \\
\hline Verrucous cancer & & & 7 & & & & & & $7(2)$ \\
\hline Basaloid SCC & & & & 5 & I & & & & $6(2)$ \\
\hline Adenocystic cancer & & & & 2 & & & 4 & & $6(2)$ \\
\hline Sarcomas & I & & & I & & & 2 & & $4(1)$ \\
\hline $\begin{array}{l}\text { Mucoepidermoid } \\
\text { cancer }\end{array}$ & & & & & & & 3 & & $3(1)$ \\
\hline MASC & & & & & & & I & & $\mathrm{I}(<\mathrm{I})$ \\
\hline $\begin{array}{c}\text { Odontogenic } \\
\text { carcinoma }\end{array}$ & & & I & & & & & & $\mathrm{I}(<\mathrm{I})$ \\
\hline $\begin{array}{c}\text { Lymphoepithelial } \\
\text { cancer, EBV+ }\end{array}$ & & I & & & & & & & $\mathrm{I}(<\mathrm{I})$ \\
\hline $\begin{array}{l}\text { Malignant } \\
\text { myoepithelioma }\end{array}$ & & & I & & & & & & $\mathrm{I}(<\mathrm{I})$ \\
\hline $\begin{array}{l}\text { Undifferentiated } \\
\text { malignant tumor }\end{array}$ & I & & & & & & I & & $2(<\mathrm{I})$ \\
\hline $\begin{array}{l}\text { Poorly differentiat- } \\
\text { ed malignant } \\
\text { tumor }\end{array}$ & & & & & & & & 2 & $2(<\mathrm{I})$ \\
\hline Small cell cancer & & & & & I & & & & $\mathrm{I}(<\mathrm{I})$ \\
\hline Acinic cell cancer & I & & & & & & I & & $2(<1)$ \\
\hline Myelosarcoma & & & & I & & & & & I $(<\mathrm{I})$ \\
\hline $\begin{array}{l}\text { Sarcomatoid spin- } \\
\text { dle cell } \\
\text { carcinoma }\end{array}$ & I & & & & & & & & $\mathrm{I}(<\mathrm{I})$ \\
\hline Total (n (\%)) & $14(4)$ & $8(2)$ & II 5 (34) & $130(39)$ & $13(4)$ & $17(5)$ & $20(6)$ & $18(5)$ & 335 \\
\hline
\end{tabular}

CUP, carcinoma unknown primary; EBV, Epstein-Barr virus; MASC, mammary analogue secretory carcinoma; SCC, squamous cell carcinoma.

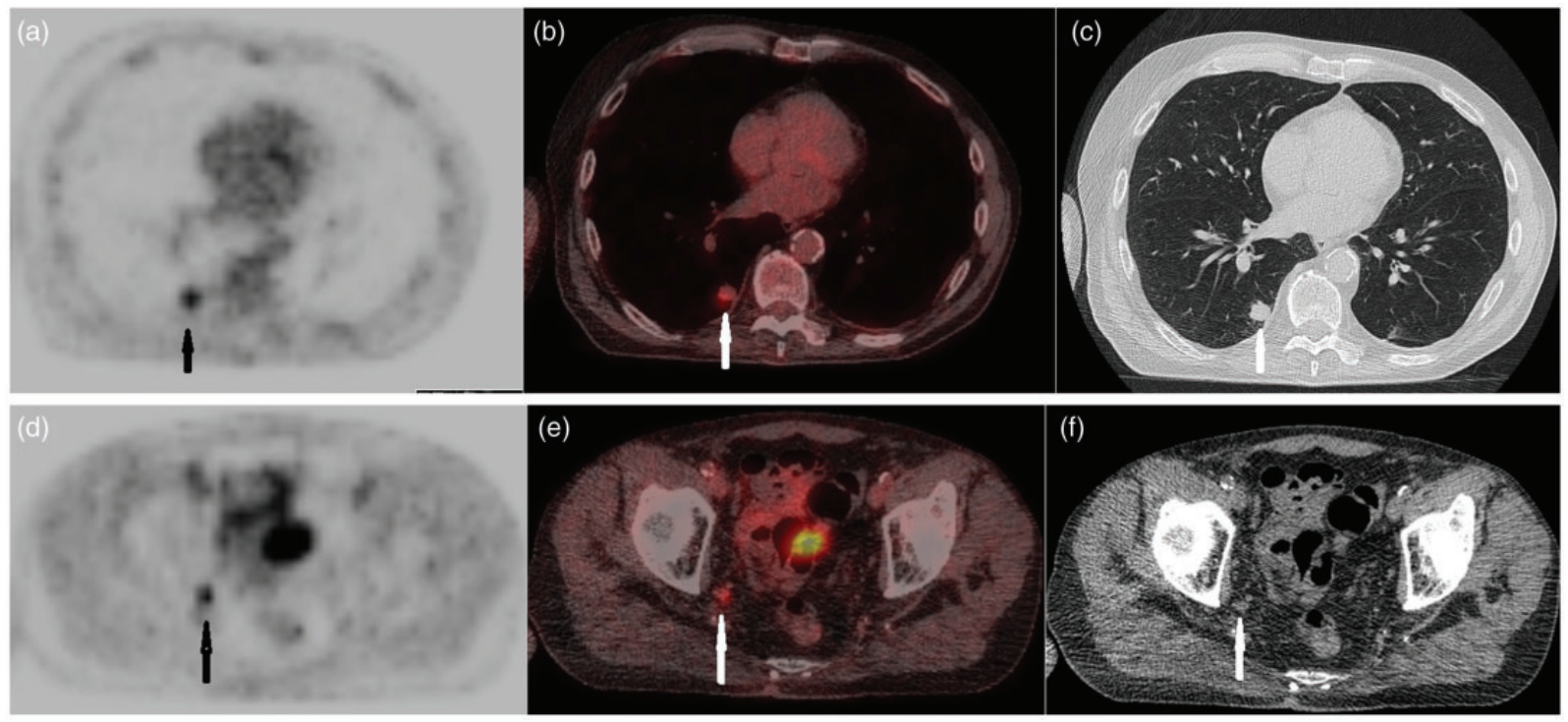

Fig. 2. Patient with oropharyngeal squamous cell carcinoma. $(a, b) \quad I 8 F-F D G-P E T / C T$ demonstrates a subpleural metastasis in right lung (arrows), clearly depicted on CT of the thorax (c). (d-f) A lymph node in lesser pelvis with slightly elevated FDG uptake was considered an equivocal finding (arrows). The patient died in palliative care seven months later from progression of neck and lung manifestations before follow-up of this lymph node. 
A

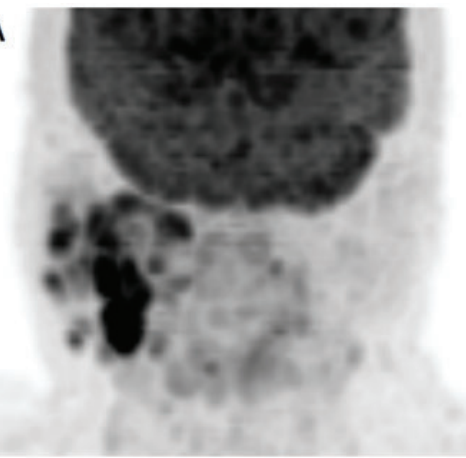

D

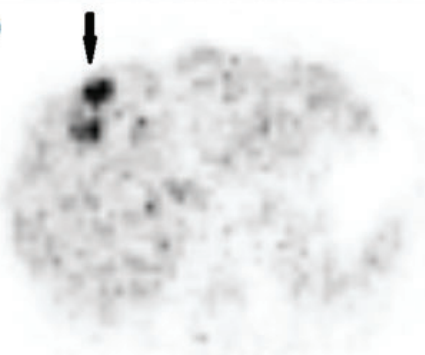

G
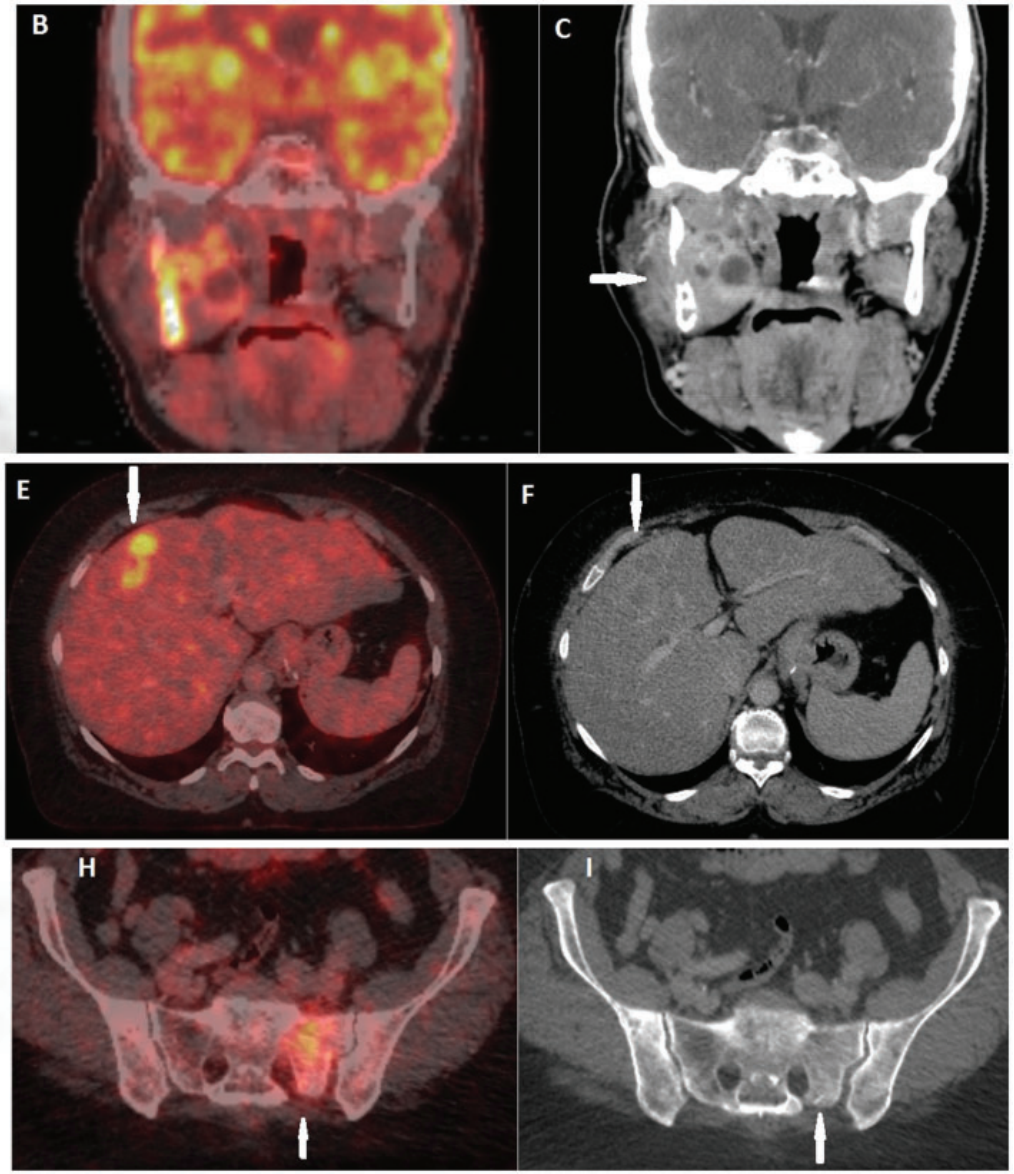

Fig. 3. Patient with a locally advanced salivary gland adenocarcinoma. (a-c) I8F-FDG-PET/CT demonstrates advanced primary tumor with mandibular invasion (white arrow). Body images reveal metastases in lower liver $(d-f)$ and sacrum ( $g-i)$. These findings would probably be overlooked on a CT of the thorax.

Table 2. Localization and histopathology of primary tumor and distant metastases in 10 patients with primary HNC and distant metastasis; staging based on locoregional spread (TN) only.

\begin{tabular}{|c|c|c|c|c|c|c|c|c|}
\hline $\begin{array}{l}\text { Primary HNC } \\
\text { location }\end{array}$ & Histopathology & $\begin{array}{l}\text { TNM } \\
\text { classification }\end{array}$ & $\begin{array}{l}\text { Staging } \\
\text { (locoregional) }\end{array}$ & $\mathrm{PI} 6$ & $\begin{array}{l}\mathrm{Ki}-67 \\
(\%)\end{array}$ & $\begin{array}{l}\text { Localization of distant } \\
\text { metastases }\end{array}$ & $\begin{array}{l}\text { Age } \\
\text { (years) }\end{array}$ & Sex \\
\hline Oropharynx & SCC & TIN3MI & IV-B & $\mathrm{N} / \mathrm{A}$ & 50 & Lung & 67 & Male \\
\hline Oropharynx & SCC & $\mathrm{T} 4 \mathrm{aN} 2 \mathrm{cMI}$ & IV-A & - & 100 & $\begin{array}{l}\text { Mediastinal lymph } \\
\text { nodes, hili, pleura, } \\
\text { thoracic wall and } \\
\text { breast. }\end{array}$ & 89 & Female \\
\hline Oropharynx & Basaloid SCC & $\mathrm{T} 2 \mathrm{~N} 2 \mathrm{bMI}$ & IV-A & + & High & Skeleton (acromion) & 60 & Male \\
\hline Hypopharynx & SCC & T4bN2bMI & IV-B & - & 100 & Lung & 77 & Male \\
\hline Larynx & SCC & T3N2bMI & IV-A & $\mathrm{N} / \mathrm{A}$ & N/A & Lung & 68 & Male \\
\hline Salivary gland & Adenocarcinoma & $\mathrm{T} 4 \mathrm{aN} 2 \mathrm{bMI}$ & IV-A & & 30 & $\begin{array}{l}\text { Liver and skeleton } \\
\text { (sacrum and collum } \\
\text { femoris) }\end{array}$ & 68 & Female \\
\hline Salivary gland & Adenocarcinoma & TN N/A, MI & N/A & & $\mathrm{N} / \mathrm{A}$ & $\begin{array}{l}\text { Lung and mediastinal } \\
\text { lymph nodes, hilus }\end{array}$ & 74 & Female \\
\hline Salivary gland & Adenocarcinoma & TN N/A, MI & $\mathrm{N} / \mathrm{A}$ & & 70 & Skeleton (L5) and lung & 91 & Female \\
\hline Salivary gland & Adenocarcinoma & T4aN3MI & IV-B & & $>75$ & $\begin{array}{l}\text { Liver, axillary lymph } \\
\text { nodes and adrenal }\end{array}$ & 63 & Male \\
\hline Salivary gland & MASC & T4aNIMI & IV-A & & 40 & Liver & 54 & Male \\
\hline
\end{tabular}

HNC, head and neck cancer; MASC, mammary analogue secretory carcinoma; SCC, squamous cell carcinoma. 
Table 3. Distribution of primary tumor and synchronous malignancies in 14 patients with HNC.

\begin{tabular}{|c|c|c|c|c|c|}
\hline $\begin{array}{l}\text { Localization } \\
\text { of HNC }\end{array}$ & TNM classification & $\begin{array}{l}\text { Histopathology } \\
\text { of HNC }\end{array}$ & Synchronous malignancies & $\begin{array}{l}\text { Age } \\
\text { (years) }\end{array}$ & Sex \\
\hline Sinus and nose & TINOMO & SCC & Hodgkin's lymphoma & 71 & Male \\
\hline Oral cavity & T2N0M0 & SCC & Lung cancer (adenocarcinoma) & 73 & Female \\
\hline Oral cavity & TINOMO & SCC & Prostate cancer (high-grade PIN) & 65 & Male \\
\hline Oral cavity & T4aNOMO & SCC & Thyroid cancer (follicular and papillary) & 79 & Male \\
\hline Oral cavity & Missing & SCC & Esophagus adenocarcinoma & 70 & Male \\
\hline Oral cavity & T2N0M0 & SCC & Thyroid cancer (follicular) and carcinoid & 70 & Female \\
\hline Oral cavity & T2N0M0 & SCC & Bladder cancer & 69 & Male \\
\hline Oral cavity & TINOMO & SCC & Esophagus cancer (SCC) & 64 & Male \\
\hline Oral cavity & T3NOMO & SCC & Thyroid cancer (papillary) & 59 & Male \\
\hline Oral cavity & T2NOMO & Verrucous cancer & Uterine cancer (serous cancer) & 86 & Female \\
\hline Oropharynx & TINIMO & SCC & Chronic lymphatic leukemia & 69 & Male \\
\hline Oropharynx & TIN2bM0 & SCC & Thyroid cancer (follicular) & 59 & Male \\
\hline CUP & TON3M0 & SCC & Bile duct cancer (adenocarcinoma) & 63 & Male \\
\hline CUP & TON2aMO & SCC & Rectal cancer (SCC) & 80 & Female \\
\hline
\end{tabular}

CUP, carcinoma unknown primary; HNC, head and neck cancer; SCC, squamous cell carcinoma.

diagnostic work-up of suspected $\mathrm{HNC}$ in recent years has increased worldwide $(6,19)$ and also why it is one of the medical imaging methods recommended by the Swedish national healthcare program for HNC (1).

The rate of distant metastases in patients with SCC in the head and neck region is relatively small in comparison to other malignancies and is related to primary tumor localization and initial TN stage. Patients with advanced regional metastatic disease ( $\mathrm{N}$ stage) have a higher frequency of distant metastases, especially in the presence of vascular ingrowth or extensive soft tissue disease (20). In our study, $10(3.0 \%)$ of 335 patients with primary $\mathrm{HNC}$ exhibited distant spreading, which is lower than in previous studies reporting distant spreading in $6 \%-21 \%(11,21)$.

The low occurrence of distant metastases in our study compared with previously reported studies might be due to several different causes. Many of the previously published studies were conducted in Asian populations with a different disease panorama. For instance, endemic forms of nasopharyngeal cancer, i.e. lymphoepithelioma, are common in south-east Asia, with incidence rates up to 9.5 per 100,000 , but rare in Scandinavia, with incidence rates $<0.5$ per $100,000(4,5)$. The public healthcare organization may also play a role. The results in our study indicate that patients in northern Sweden generally seek medical care early in the course of disease compared with an international context, which may explain a lower tumor grade at diagnosis and hence less risk for tumor spreading. For example, the clinical course and prognosis of cancer of the salivary glands vary greatly, depending on histopathological subtype. The most important factors predicting survival outcomes are histological grade and clinical stage at presentation (13).
The majority of the distant metastases, 14 of 21 findings, were located in the thoracic region, which is slightly lower than reported in a recently published Danish study on oropharyngeal and laryngeal cancer, in which all patients with distant metastases $(18 / 307)$ had thoracic involvement (7). In this study, all nine distant metastases from a head and neck SCC were situated above the diaphragm; all but one could be identified by $\mathrm{CT}$ of the thorax alone. The difference between the present study and the Danish study is attributed to the salivary gland malignancies included in our material, which were responsible for all sub-diaphragmal metastases.

A surprisingly high proportion of adenocarcinomas, 4 out of 11 cases, had distant spreading. These four adenocarcinomas were located in the major salivary glands and accounted for half of all salivary gland adenocarcinomas.

Twenty-five percent $(5 / 20)$ of the primary salivary gland malignancies exhibited distant spreading. This is a higher proportion than previously reported by Park et al. (10), who reported distant spread in $6 \%$, but more in line with a recent North American study, which showed that $20 \%$ of patients with cancer of the salivary glands had distant metastases, especially in the lungs (22). This could be predicted by several clinical and pathological factors, such as histologically high malignancy level, locally advanced tumor growth, perineural invasion, and $\mathrm{N}$ stage (22).

The proportion of patients with synchronous malignancies, $4.2 \%$ (14 of 335) in this study, falls within the range of previously published rates of $2.3 \%-12 \%$ $(6,7,23-26)$.

One drawback with FDG-PET/CT is nodal staging in $\mathrm{HNC}$, in which the method has a low specificity, 
meaning that a considerable number of false-positive findings are detected (e.g. reactive lymph nodes); in this sense, it has a restricted positive predictive value $(9,27)$. A general limitation of radiological methods available today is also a limited sensitivity for microtumors, posing a diagnostic restraint, especially in patients with limited disease and clinical $\mathrm{N}_{0}$ head and neck cancers (28). Although the value of whole-body FDG-PET/CT for screening of distant spread has been proven in patients with increased risk factors (29-31), this is not necessarily transferable to patient groups with limited disease and no other evident risk factors for metastases. The diagnostic value of performing a FDG-PET/CT in addition to $\mathrm{CT}$ or MRI in patients with oropharyngeal SCC without clinically palpable cervical lymph nodes has been disputed in previous studies $(32,33)$. In contrast, other studies show a high negative predictive value of FDG-PET/CT for cervical nodal staging in HNC patients (17). This is of value mainly in regimes with elective neck dissection. However, such regimes have been challenged even in advanced HNC by the results from a recent study by Mehanna et al. (34) where survival rates were similar among patients who underwent PET-CT guided surveillance and those who underwent planned neck dissection.

Since there were few patients with distant metastases and synchronous malignancies in this study, it could be debated whether it is optimal to perform whole-body FDG-PET/CT in all patients with clinical suspicion of HNC. In a recent Danish study by Krabbe et al., there was no difference in the rate of detection between a CT of the thorax and FDG-PET for the detection of intrathoracic distant metastases (30), which is in line with our findings concerning the distant metastases in the thorax, of which all but one of the metastases were detectable with only CT. In addition, the risk for distant spread is low in patients with SCC stage 1-2. In fact, all patients with distant spreading in our study had locoregionally advanced tumors corresponding to $\mathrm{TN}(\mathrm{M})$ stage 3-4. Therefore, it may be reasonable to use contrast-enhanced CT or MRI of the neck and CT of the thorax for initial staging in patients with limited disease, that is, clinical stage 1 or 2 . In contrast, for patients with advanced locoregional tumor disease as well as in patients with adenocarcinomas, who according to our results seem to have a higher risk of distant spreading (e.g. skeletal metastases or metastases distal to the diaphragm), a whole-body FDG-PET/CT may add important diagnostic information in the initial pretherapeutic work-up. Based on our results, another potentially useful strategy in HNC patients with clinically limited disease could be the use of FDG-PET/MR for locoregional staging combined with a (preferably contrast-enhanced) $\mathrm{CT}$ of the thorax for the detection of distant spread. According to our own limited experience, FDG-PET/MR occasionally offers superior visualization and delineation of the primary tumor compared to FDG-PET/CT, especially in the suprahyoid region. This is primarily due to the superior soft-tissue differentiation offered by MR. The superiority of FDG-PET/MR is also proposed in a comparative study on nasopharyngeal carcinomas, conducted with non-contrast-enhanced FDG-PET/CT versus contrast-enhanced FDG-PET/MR (12). The results from other studies comparing FDG-PET/MR to FDG-PET/CT in HNC patients, however, remain equivocal (35). The choice of hybrid modality for assessment of HNC M-stage remain a delicate balance between perspectives. As PET/MR is a slow modality it is not well-suited for whole-body imaging; another caveat is the limited availability and high cost of such equipment. A compromise to consider when choosing hybrid imaging modality for the detection of distant metastases in HNC may be the different performance of CT and MRI in specific morphological detection. Small lung metastases are better detected with CT (even without contrast enhancement), while MR is superior for the detection of small liver metastases. In both instances, the FDG uptake in such small lesions may be ambiguous due to respiration artefacts and limited spatial resolution.

The study group consisted of patients from northern Sweden only and there are no similar, comparable published data on the general population of Sweden, which limits the generalization of the results. However, there is no obvious reason to believe that the panorama of disease would be substantially different in other parts of the country; some of our results correlate well with previous studies in similar Scandinavian populations (31). Another limitation is that in this retrospective study, including only patients with FDG-PET/CT in the primary diagnostic work-up, it is possible that we missed patients with especially minor salivary gland malignancies. In addition, we excluded early-stage laryngeal cancer, which constitutes a non-negligible part of $\mathrm{HNC}$, since these patients rarely undergo FDG-PET/CT in the pre-treatment work-up; this may affect comparison with other studies on HNC. A prospective study including FDG-PET/CT in laryngeal cancer might be valuable in assessing the diagnostic value of this entity. Although the study group consisted of a large number of patients from a vast catchment area, the subgroups remain small, making it difficult to draw conclusions based on specific histology or tumor location. As the spectrum of HNC includes a diverse range of tumors with different behaviors, this weakness is shared with most, if not all, previous studies on the subject. Still, since it is of interest to map the entire panorama of the different HNC subtypes in respect of the risk for distant spread and potential concurrent 
synchronous malignancies, a larger cohort comprising data from several hospitals would be advocated for improved statistical foundation and representativeness.

In conclusion, the results confirms that the risk for distant spread or synchronous malignancies below the diaphragm is low in patients with HNC primary squamous cell carcinoma stages 1 and 2 . In such patients without clinical evidence of nodal disease, the use of contrast-enhanced CT or MRI or FDG-PET/MR of the neck and $\mathrm{CT}$ of the thorax for initial staging may be a reasonable approach. However, in patients with advanced HNC, especially salivary gland adenocarcinoma, the risk of distant spreading is higher, thus motivating whole-body FDG-PET/CT in the primary diagnostic work-up.

\section{Declaration of conflicting interests}

The authors declared no potential conflicts of interest with respect to the research, authorship, and/or publication of this article.

\section{Funding}

The authors received the following financial support for the research, authorship, and/or publication of this article: Financial support was provided through regional agreement between Umeå University and Västerbotten County Council on cooperation in the field of Medicine, Odontology and Health (ALF) (TUA).

\section{ORCID iD}

Lennart Flygare (D) https://orcid.org/0000-0001-8229-5428

\section{References}

1. Regionala cancercentrum i samverkan. Huvud- och halscancer: nationellt vårdprogram. Stockholm: RCC, 2019 (in Swedish). Available at: https://www.cancercentrum. se/globalassets/cancerdiagnoser/huvud-och-hals/vardpro gram/nationellt-vardprogram-huvud-halscancer.pdf (accessed 15 May 2019).

2. International Agency for Research on Cancer. Estimated cancer incidence, mortality and prevalence worldwide in 2018. Lyon: WHO, 2019. Available at: http://gco.iarc.fr/ (accessed 3 June 2019).

3. Swedish National Board of Health and Welfare. Internationell statistisk klassifikation av sjukdomar och relaterade hälsoproblem - Systematisk förteckning, svensk version. Stockholm: SoS, 2011 (in Swedish). Available at: www.socialstyrelsen.se/klassificeringoch koder/diagnoskodericd-10. Accessed 15 Jun 2018

4. Salehiniya H, Mohammadian M, MohammadianHafshejani A, et al. Nasopharyngeal cancer in the world - epidemiology, incidence, mortality and risk factors. World Cancer Res J 2018;5:8.
5. Curado MP, Edwards B, Shin HR, et al., editors. Cancer incidence in five continents. Vol. 9. IARC Scientific Publications No. 160. Lyon: IARC, 2007.

6. Xu G-Z, Guan D-J, He Z-Y. 18FDG-PET/CT for detecting distant metastases and second primary cancers in patients with head and neck cancer. A meta-analysis. Oral Oncol 2011;47:560-565.

7. Rohde M, Nielsen AL, Johansen J, et al. Head-to-head comparison of chest X-ray/head and neck MRI, chest $\mathrm{CT} /$ head and neck MRI, and 18 F-FDG PET/CT for detection of distant metastases and synchronous cancer in oral, pharyngeal, and laryngeal cancer. J Nucl Med 2017;58:1919-1924.

8. Jeong H-S, Chung MK, Son Y-I, et al. Role of 18F-FDG PET/CT in management of high-grade salivary gland malignancies. J Nucl Med 2007;48:1237-1244.

9. Kim SY, Roh J-L, Yeo N-K, et al. Combined 18F-fluorodeoxyglucose-positron emission tomography and computed tomography as a primary screening method for detecting second primary cancers and distant metastases in patients with head and neck cancer. Ann Oncol 2007; 18:1698-1703.

10. Park MJ, Oh JS, Roh J-L, et al. 18F-FDG PET/CT versus contrast-enhanced $\mathrm{CT}$ for staging and prognostic prediction in patients with salivary gland carcinomas. Clin Nucl Med 2017;42:e149-e156.

11. Deurvorst SE, Hoekstra OS, Castelijns JA, et al. Clinical value of 18 FDG PET/CT in screening for distant metastases in head and neck squamous cell carcinoma. Clin Otolaryngol 2018;43:875-881.

12. Chan S, Yeh, C, Yen T, et al. Clinical utility of simultaneous whole-body $18 \mathrm{~F}-\mathrm{FDG}$ PET/MRI as a single step modality in the staging of primary nasopharyngeal carcinoma. Eur J Nucl Med Mol Imaging 2018;45:1297-1308.

13. Ren Y, Li Y, Wu H, et al. Whole-body 18 F-FDG PET/ $\mathrm{CT}$ for $\mathrm{M}$ staging in the patient with newly diagnosed nasopharyngeal carcinoma: Who needs? Eur J Radiol 2017;89:200-207.

14. Kyzas PA, Evangelou E, Denaxa-Kyza D, et al. 18Ffluorodeoxyglucose positron emission tomography to evaluate cervical node metastases in patients with head and neck squamous cell carcinoma: a meta-analysis. J Natl Cancer Inst 2008;100:712-720.

15. Sun R, Tang X, Yang Y, et al. 18FDG-PET/CT for the detection of regional nodal metastasis in patients with head and neck cancer: A meta-analysis. Oral Oncol 2015;51:314-320.

16. Petersen H, Holdgaard PC, Madsen PH, et al. FDG $\mathrm{PET} / \mathrm{CT}$ in cancer: comparison of actual use with literature-based recommendations. Eur J Nucl Med Mol Imaging 2016;43:695-706.

17. Sanli Y, Zukotynski K, Mittra E, et al. Update 2018: 18F-FDG PET/CT and PET/MRI in head and neck cancer. Clin Nucl Med 2018;43:e439-e452.

18. Brierley JD, Gospodarowicz MK, Wittekind C, editors. UICC TNM classification of malignant tumours. 8th edn. Chichester: Wiley Blackwell, 2017.

19. Senft A, Hoekstra OS, Castelijns JA, et al. Pretreatment screening for distant metastases in the Dutch head and 
neck centers: 10 years later. Eur Arch Otorhinolaryngol 2016;273:3287-3291.

20. Ferlito A, Shaha AR, Silver CE, et al. Incidence and sites of distant metastases from head and neck cancer. ORL J Otorhinolaryngol Relat Spec 2001;63:202-207.

21. Lonneux M, Hamoir M, Reychler H, et al. Positron emission tomography with [18 F]fluorodeoxyglucose improves staging and patient management in patients with head and neck squamous cell carcinoma: a multicenter prospective study. J Clin Oncol 2010;28:1190-1195.

22. Ali S, Bryant R, Palmer FL, et al. Distant metastases in patients with carcinoma of the major salivary glands. Ann Surg Oncol 2015;22:4014-4019.

23. Ng S-H, Chan S-C, Liao C-T, et al. Distant metastases and synchronous second primary tumors in patients with newly diagnosed oropharyngeal and hypopharyngeal carcinomas: evaluation of 18F-FDG PET and extended-field multi-detector row CT. Neuroradiology 2008;50:969-979.

24. Brouwer J, Senft A, de Bree R, et al. Screening for distant metastases in patients with head and neck cancer: Is there a role for 18FDG-PET? Oral Oncol 2006;42:275-280.

25. Erkal H, Mendenhall W, Amdur R, et al. Synchronous and metachronous squamous cell carcinomas of the head and neck mucosal sites. J Clin Oncol 2001;19:1358-1362.

26. Jäckel MC, Reischl A, Huppert P. Efficacy of radiologic screening for distant metastases and second primaries in newly diagnosed patients with head and neck cancer. Laryngoscope 2007;117:242-247.

27. Cetin B, Atasever T, Akdemir UO, et al. The role of positron emission tomography with $18 \mathrm{~F}$-fluorodeoxyglucose in nodal staging of clinical and radiological N0 head and neck cancers. Eur Arch Otorhinolaryngol 2013;270:2307-2313.
28. Wensing BM, Vogel WV, Marres HAM, et al. FDG-PET in the clinically negative neck in oral squamous cell carcinoma. Laryngoscope 2006;116:809-813.

29. Senft A, de Bree R, Hoekstra OS, et al. Screening for distant metastases in head and neck cancer patients by chest CT or whole body FDG-PET: A prospective multicenter trial. Radiother Oncol 2008;87:221-229.

30. Gourin CG, Watts TL, Williams HT, et al. Identification of distant metastases with positron-emission tomographycomputed tomography in patients with previously untreated head and neck cancer. Laryngoscope 2008; 118:671-675.

31. Krabbe CA, Pruim J, van der Laan BFAM, et al. FDGPET and detection of distant metastases and simultaneous tumors in head and neck squamous cell carcinoma: A comparison with chest radiography and chest CT. Oral Oncol 2009;45:234-240.

32. Sohn B, Koh YW, Kang WJ, et al. Is there an additive value of 18 F-FDG PET-CT to CT/MRI for detecting nodal metastasis in oropharyngeal squamous cell carcinoma patients with palpably negative neck? Acta Radiol 2016;57:1352-1359.

33. Krabbe CA, Dijkstra PU, Pruim J, et al. FDG PET in oral and oropharyngeal cancer. Value for confirmation of N0 neck and detection of occult metastases. Oral Oncol 2008;44:31-36.

34. Mehanna H, Wong W-L, McConkey CC, et al. PET-CT surveillance versus neck dissection in advanced head and neck cancer. N Engl J Med 2016;374:1444-1454.

35. Morsing A, Hildebrandt M, Vilstrup, M et al. Hybrid PET/MRI in major cancers: a scoping review. Eur $\mathbf{J}$ Nucl Med Mol Imaging 2019;46:2138-2151. 